AL-Qadisiyah Journal of pure Science $\quad$ Vol.23 No.2 $\quad$ Year 2018

\title{
S- Anti Fuzzy M-Semigroup
}

\section{Farhan Dakhil Shyaa}

Department of Mathematics University of Al-Qadsiyah, College of Education, Al-Qadsiyah, Iraq Farhan.Shyaa@qu.edu.iq, farhan_math1@yahoo.co.uk

Received:- 13/1/2017

Accepted:-12/3/2017

\begin{abstract}
$\underline{\text { Abstract }}$
In this paper, we define the concept of a smarandache anti fuzzy M-semigroup (S-Anti Fuzzy MSemigroup) and some elementary properties about this concept are discussed.
\end{abstract}

Key words: Fuzzy sets, semigroup, M-semigroup

Physical Classification QA 150- 272.5 


\section{Introduction}

In 1965 Zadeh introduced the concept of fuzzy set[1], in 1971 Rosenfeld formulated the term of fuzzy subgroup[2]. In 1994 W.X.Gu , S.Y.Li and D.G.Chen studied fuzzy groups and gave some new concepts as M- fuzzy groups [3] . In 2002 W.B.Vasantha introduced the concepts of smarandache semigroups[4]. Smarandache fuzzy semigroups are studied in 2003 by W.B.Vasantha[5] . In 2011 H.R.Yassein and M.O.Karim introduced the concept of a smarandache $\mathrm{M}$ - semigroup (S-M-semigroup) and studied some basic properties [6].

In this paper, the concept of Smarandache antifuzzy M semigroup are given and its some elementary properties are discussed

\section{1- Preliminaries}

Definition (1.1): Let $G$ be a group. A fuzzy subset $\mu$ of a group $G$ is called anti fuzzy subgroup of the group $\mathrm{G}$ if:

$1-\mu(x y) \leq \max \{\mu(x), \mu(y)\}$ for every $x, y \in G$.

2. $\mu(x)=\mu\left(x^{-1}\right)$ for every $x \in G$. [7]

Definition (1.2): A semigroup $H$ with operators is an algebraic system consisting of a semigroup $\mathrm{H}$, set $\mathrm{M}$, and a function defined in the product $\mathrm{M} \times \mathrm{H}$ and having values in $\mathrm{H}$ such that, if ma denotes the element in $\mathrm{H}$ determined by the element $\mathrm{a}$ in $\mathrm{H}$ and the element $\mathrm{m}$ in $\mathrm{M}$, then $\mathrm{m}(\mathrm{ab})=(\mathrm{ma})(\mathrm{mb}), \mathrm{a}, \mathrm{b} \in \mathrm{H}$ and $\mathrm{m} \in \mathrm{M}$ then $\mathrm{H}$ is $\mathrm{M}$ - semigroup [3].

We shall usually use the phrase "G is an Mgroup" to a group with operators.
Definition (1.3): If $\mu$ is a fuzzy set of $G$ and $t \in$ [0,1] then $\mu_{\mathrm{t}}=\{\mathrm{x} \in \mathrm{G} \mid \mu(\mathrm{x}) \leq \mathrm{t}\} \quad$ is called a $\mathrm{t}$ level set $\mu$ [6].

Definition (1.4): Let $G$ and $G^{\prime}$ both be $M-$ groups, $f$ be a homomorphism from $G$ onto $G^{\prime}$, if $f(m x)=m f(x)$ for every $m \in M, x \in X$, then $f$ is called a $\mathrm{M}$-homomorphism [5].

Definition (1.5): Let $S$ be a semigroup,$S$ is said to be a smarandache semigroup ( $\mathrm{S}$ semigroup ) if $\mathrm{S}$ has a proper subset $\mathrm{P}$ such that $P$ is a group under the operation of $G$ [5].

Definition (1.6): Let $G$ be any group. A mapping $\mu: \mathrm{G} \rightarrow[0,1]$ is a fuzzy group if (1) $\mu$ $(x y) \geq \min \{\mu(x), \mu(y)\}(2) \mu(x-1)=\mu(x)$ for all $\mathrm{x}, \mathrm{y} \in \mathrm{G}[1]$.

Definition (1.7): Let $\mathrm{H}$ be $\mathrm{M}$ - semigroup . $\mathrm{H}$ is said to be a smarandache $\mathrm{M}$ - semigroup (S-Msemigroup) if $\mathrm{H}$ has a proper subset $\mathrm{K}$ such that $\mathrm{K}$ is $\mathrm{M}$ - group under the operation of $\mathrm{H}$ [6].

this S- fuzzy semigroup is denoted by $\mu_{\mathrm{p}}: \mathrm{P} \rightarrow$ $[0,1]$ is fuzzy group .

Definition(1.8) : A group with operators is an algebraic system consisting of a group $\mathrm{G}$, set $\mathrm{M}$ and a function defined in the product $M \times G$ and having value in $G$ such that, if ma denotes the elements in $\mathrm{G}$ determined by the element $\mathrm{m}$ of $\mathrm{M}$, then $\mathrm{m}(\mathrm{ab})=(\mathrm{ma})(\mathrm{mb})$ hold for all $\mathrm{a}, \mathrm{b}$ in $\mathrm{G}$ , $\mathrm{m}$ in $\mathrm{M}$ [3].

Definition (1.9): Let $\mathrm{H}$ be a $\mathrm{S}$ - $\mathrm{M}$-semigroup. A fuzzy subset $\mu: H \rightarrow[0,1]$ is said be smarandache fuzzy M-semigroup if $\mu$ restricted to at least one subset $\mathrm{K}$ of $\mathrm{H}$ which is subgroup is fuzzy subgroup[2]. 
Definition (1.10): Let $S$ and $S^{\prime}$ be any two $S$ semigroups . A map $\varphi$ from $S$ to $S^{\prime}$ is said to be $S$ - semigroup homomorphism if $\varphi$ restricted to a subgroup $A \subset S \rightarrow A^{\prime} \subset S^{\prime} \quad$ is a group homomorphism [2].

Definition (1.11): Let $\mathrm{H}$ and $\mathrm{K}$ be any two $\mathrm{S}$ M- semigroup . A map $\varphi$ from $H$ to $K^{\prime}$ is said to be S-M- semigroup homomorphism if $\varphi$ restricted to a M- subgroup $\mathrm{A} \subset \mathrm{H} \rightarrow \mathrm{A}^{\prime} \subset \mathrm{K}^{\prime} \quad$ is M- homomorphism [6].

Definition (1.12): Let $f$ be a function from a set $\mathrm{X}$ to a set $\mathrm{Y}$ while $\mu$ is fuzzy set of $\mathrm{X}$ then the image $f(\mu)$ of $\mu$ is the fuzzy set $f(\mu): Y \rightarrow[0,1]$ defined by : [7]

$$
f(\mu(y))= \begin{cases}\sup \mu(x) & \text { if } f^{-1}(y) \neq \phi \\ x \in f^{-1}(y) & \\ 0 & \text { if } f^{-1}(y)=\phi\end{cases}
$$

Definition (1.13): Let $\mathrm{f}$ be a function from a set $X$ to a set $Y$ while $\mu$ is fuzzy set of $Y$ then the inverse image $\mathrm{f}^{-1}(\mu)$ of $\mu$ under $\mathrm{f}$ is the fuzzy set $\mathrm{f}^{-1}(\mu): X \rightarrow[0,1]$ defined by $\mathrm{f}^{-1}(\mu)(\mathrm{x})=$ $\mu(\mathrm{f}(\mathrm{x}))[7]$.

\section{2-The Main Results}

In this section we shall define Smarandache anti fuzzy M-semigroup and give some its results.

Definition (2.1): Let $G$ be $M$ - group and $\mu$ be anti fuzzy subgroup of $G$ if $\mu(m x) \leq \mu$ (x) for every $x \in G, m \in M$,then $\mu$ is said to be anti fuzzy subgroup with operators of $G$, we use the pharse $\mu$ is an $M$ - anti fuzzy subgroup of $G$ instead of a fuzzy subgroup with operators of G .
Definition (2.2): Let $\mathrm{S}$ be an S-semigroup. A fuzzy subset $\mu: S \rightarrow[0,1]$ is said to be Smarandache anti fuzzy semigroup ( $S$ - anti fuzzy semigroup ) if $\mu$ restricted to at least one subset $\mathrm{P}$ of $\mathrm{S}$ which is a subgroup is anti fuzzy subgroup .

that is for all $\mathrm{x}, \mathrm{y} \in \mathrm{P} \subset \mathrm{S}, \mu\left(\mathrm{xy}^{-1}\right) \leq \max \{\mu(\mathrm{x})$ , $\mu(\mathrm{y})\}$.

Definition (2.3): Let $\mathrm{H}$ be a S-M- semigroup. A fuzzy subset $\mu: \mathrm{H} \rightarrow[0,1]$ is said to be Smarandache anti fuzzy M-semigroup if restricted to at least one subset $\mathrm{K}$ of $\mathrm{H}$ which is anti fuzzy M- subgroup

Proposition (2.4): If $\mu$ is S-anti fuzzy $M$ semigroup of S-M- semigroup then:

1) $\mu_{\mathrm{K}}(\mathrm{m}(\mathrm{xy})) \leq \max \left\{\mu_{\mathrm{K}}(\mathrm{mx}), \mu_{\mathrm{k}}(\mathrm{my})\right\}$

2) $\mu_{k}\left(m x^{-1}\right) \leq \mu_{k}(x)$

For all $\mathrm{m} \in \mathrm{M}, \mathrm{x}, \mathrm{y} \in \mathrm{K}$

Proof: $\mu$ is $S$ - fuzzy M-semigroup

Then there exist subset $\mathrm{K}$ of $\mathrm{H}$ which is $\mathrm{M}$ subgroup such $\mu$ restricted of $K$ which is antifuzzy

i.e . $\mu_{\mathrm{K}}: \mathrm{K} \rightarrow[0,1], \mathrm{M}$ - anti fuzzy subgroup

for all $\mathrm{x}, \mathrm{y} \in \mathrm{K}, \mathrm{m} \in \mathrm{M}$, it is clear that

$$
\text { 1) } \begin{aligned}
\mu_{\mathrm{K}}(\mathrm{m}(\mathrm{xy})) & \leq \mu_{\mathrm{K}}((\mathrm{mx})(\mathrm{my})) \\
\text { 2) } \mu_{\mathrm{k}}\left(m x^{-1}\right) & \leq \mu_{\mathrm{k}}(\mathrm{mx})^{-1} \\
& \leq \mu_{\mathrm{K}}(\mathrm{mx})
\end{aligned}
$$

Proposition (2.5): Let $\mathrm{G}$ be $\mathrm{S}$ - semigroup , $\mu$ fuzzy set of G. Then $\mu$ is an S- anti fuzzy Msemigroup of $\mathrm{G}$ if and only if $\mathrm{f} \forall \mathrm{t} \in[0,1], \mu_{\mathrm{t}}$ is an S-M- semigroup $\mu_{\mathrm{t}} \neq \varnothing$. 
Proof: It is clear $\mu_{\mathrm{t}}$ is semigroup of $\mathrm{G}$ while $\mu_{\mathrm{t}}$ $\neq \varnothing$ holds.

for any $\mathrm{x} \in \mu_{\mathrm{t}}, \mathrm{m} \in \mathrm{M}$

$\mu(\mathrm{mx}) \leq \mu(\mathrm{x}) \leq \mathrm{t}$

hence $\mathrm{mx}$ in $\mu_{\mathrm{t}}$, hence $\mu_{\mathrm{t}}$ is an M- semigroup of $\mathrm{G}$.

Since $\mu$ S-anti fuzzy $\mathrm{M}$ - semigroup $\exists \mathrm{K} \subset \mathrm{G}$ subgroup $\ni \mu_{t}: K \rightarrow[0,1]$

fuzzy M- subgroup.

$\mu_{\mathrm{K}_{t}}=\left\{\mathrm{x} \in \mathrm{K} \mid \mu_{\mathrm{K}}(\mathrm{x}) \leq \mathrm{t}\right\}$.

It is clear $\mu_{\mathrm{K}_{t}}$ is group. Hence $\mu_{\mathrm{t}} \mathrm{S}-\mathrm{M}$ semigroup .

Conversely, Since $\mu_{\mathrm{t}}$ S-M- semigroup then there exists a proper subset $\mathrm{K}$ of $\mathrm{G}$ such that $\mathrm{K}$ is M-subgroup .

If there exists $\mathrm{x} \in \mathrm{K}, \mathrm{m} \in \mathrm{M}$ such that $\mu_{\mathrm{K}}(\mathrm{mx})$ $>\mu_{\mathrm{K}}(\mathrm{x})$.

let $\mathrm{t}=\frac{1}{2}\left(\mu_{\mathrm{K}}(\mathrm{mx})+\mu_{\mathrm{K}}(\mathrm{x})\right)$ then $\mu_{\mathrm{K}}(\mathrm{x})<\mathrm{t}<$

$\mu_{\mathrm{K}}(\mathrm{mx}) \quad \mathrm{mx} \notin \mu_{\mathrm{K}_{t}}$ so here emerges a contradiction .

$\mu_{\mathrm{K}}(\mathrm{mx}) \leq \mu_{\mathrm{K}}(\mathrm{x})$ always holds for any $\mathrm{x} \in \mathrm{K}, \mathrm{m} \in$ $\mathrm{M}$.

$\mu_{\mathrm{K}}$ is M- fuzzy subgroup hence $\mu$ is $\mathrm{S}$-anti

fuzzy M- subgroup.

Proposition (2.6): Let $\mathrm{H}$ and $\mathrm{K}$ both be S-Msemigroup and $\mathrm{f}$ as $\mathrm{S}-\mathrm{M}$ - semigroup homomorphism from $H$ onto $K$. if $\mu^{\prime}$ is an $S$ anti fuzzy M- semigroup

of $\quad \mathrm{H}^{\prime}$ then $\mathrm{f}^{-1}\left(\mu^{\prime}\right)$ is an S-anti fuzzy Msemigroup of $\mathrm{H}$.
Proof:

Since $\mathrm{f}: \mathrm{H} \rightarrow \mathrm{K}$ is as $\mathrm{S}-\mathrm{M}$ - semigroup homomorphism then $\mathrm{f}$ restricted to $\mathrm{M}$ subgroup .

$\mathrm{A} \subset \mathrm{H} \rightarrow \mathrm{B} \subset \mathrm{K}$ is $\mathrm{M}$ - homomorphism,

$\mathrm{f}^{-1}(\mu)_{\mathrm{A}}: \mathrm{A} \rightarrow[0,1]$ such that A M-subgroup ,

For any $\mathrm{m} \in \mathrm{M}, \mathrm{x} \in \mathrm{A}$

$$
\begin{aligned}
\mathrm{f}^{-1}(\mu)_{\mathrm{A}}(\mathrm{mx}) & =\mu^{\prime}{ }_{\mathrm{A}}(\mathrm{f}(\mathrm{mx})) \\
& =\mu^{\prime}{ }_{\mathrm{A}}(\mathrm{m}(\mathrm{f}(\mathrm{x})) \leq
\end{aligned}
$$

$\mu_{A}^{\prime}(f(x))$

$$
=f^{-1}\left(\mu^{\prime}\right)(x)
$$

$\mathrm{f}^{-1}\left(\mu^{\prime}\right)$ is S-anti fuzzy M- semigroup

Proposition (2.7): Let $\mathrm{H}$ and $\mathrm{K}$ both be S-Msemigroups and $\mathrm{f}$ as $\mathrm{S}-\mathrm{M}$ - semigroup homomorphism from $H$ onto $K$. if $\mu$ is an S-anti fuzzy M- semigroup of $H$ then $f(\mu)$ is an S-anti fuzzy M-semigroup of $\mathrm{K}$.

\section{Proof:}

Since $\mathrm{f}: \mathrm{H} \rightarrow \mathrm{K}$ is as $\mathrm{S}-\mathrm{M}$ - semigroup homomorphism then $\mathrm{f}$ restricted to $\mathrm{M}$ subgroup .

$\mathrm{A} \subset \mathrm{H} \rightarrow \mathrm{B} \subset \mathrm{K}$ is $\mathrm{M}$ - homomorphism

$\mathrm{f}(\mu)_{\mathrm{B}^{\prime}}: \mathrm{B} \rightarrow[0,1]$ such that B M-subgroup ,

For any $\mathrm{m} \in \mathrm{M}, \mathrm{y} \in \mathrm{B}$

$$
\begin{aligned}
\mathrm{f}(\mu)(\mathrm{my}) & =\sup \mu(\mathrm{x}), \mathrm{x} \mathrm{f}^{-1}(\mathrm{my}) \\
= & \{\sup \mu(\mathrm{x}), \mathrm{f}(\mathrm{x})=\mathrm{my} \\
, \mathrm{mx}^{\prime} \in \mathrm{H} \quad & \leq \sup \mu\left(\mathrm{mx}^{\prime}\right), \mathrm{f}\left(\mathrm{mx}^{\prime}\right)=\mathrm{mx}
\end{aligned}
$$




$$
\begin{array}{ll}
, \mathrm{mx}^{\prime} \in \mathrm{H} & =\sup \mu\left(\mathrm{x}^{\prime}\right), \operatorname{mf}\left(\mathrm{x}^{\prime}\right)=\mathrm{my} \\
\in \mathrm{H} & \leq \sup \mu\left(\mathrm{x}^{\prime}\right), \mathrm{f}\left(\mathrm{x}^{\prime}\right)=\mathrm{y}, \mathrm{x}^{\prime} \\
& \\
& =\mathrm{f}(\mu)(\mathrm{y})
\end{array}
$$

hence $\mathrm{f}^{-1}\left(\mu^{\prime}\right)$ is $\mathrm{S}$ - anti fuzzy $\mathrm{M}$ - semigroup

\section{$\underline{\text { References }}$}

[1] L.A. Zadeh"Fuzzy sets" INFORATIOAND CONTROL 8, 338--353 (1965).

[2] A. Rosenfeld Fuzzy groups, Journal of mathematical Analysis and Applications , 35, 512- 517, 1971.

[3] W.X.Gu , S.Y.Li and D.G.Chen, "Fuzzy Groups with Operators ", Fuzzy sets and system , 66 (363-371), 1994 .

[4] W.B.Vasantha, "Smarandache

Semigroups", American research press ,2002.
[5] ] W.B.Vasantha ,"Smarandache Fuzzy

Algebra ", American research press , 2003.

[6] H.R.Yassein and M.O.Karim " On Smarandache M-Semigroup " Journal of AL_Qadisiya for pure science "vol.3, no.1, 71-76, 2011 .

[7] K.A.Al-Shamari, "An Annalus Approach To Fuzzy Subgroup ", M.Sc. thesis, Saudui Arabia, 1998.

[8] R .Muthurage ," Anti Q-Fuzzy Group and Its Lower Level Subgroups" International journal of computer applications, Volume 3, No.3 , 2010.

$$
\begin{aligned}
& \text { ضد شبه الزمرة - S-M الضبابية } \\
& \text { فرحان داخل شياع } \\
& \text { جامعه القادسيه / كليه التربيه / قسم الرياضيات }
\end{aligned}
$$

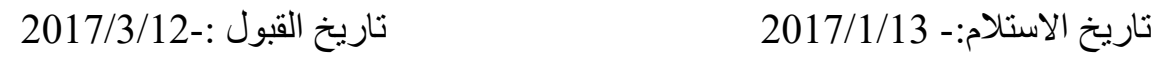

